\title{
O Programa Paraná Competitivo e seu efeito na dinâmica econômica dos municípios paranaenses: uma análise espacial ${ }^{1}$
}

\author{
Augusta Pelinski Raiher \\ Universidade Estadual de Ponta Grossa \\ Hermes Higachi \\ Universidade Estadual de Ponta Grossa \\ Alex Sander Souza do Carmos \\ Universidade Estadual de Ponta Grossa
}

\begin{abstract}
Resumo
O objetivo deste trabalho é analisar a efetividade do programa Paraná Competitivo na dinâmica econômica dos municípios do Paraná, entre 2010 e 2014. Para isso, a econometria espacial foi utilizada com o intuito de verificar o efeito do programa na variação do emprego industrial, do emprego total, da massa salarial e da média salarial. Como corolário, tem-se um processo de descentralização da indústria paranaense e o Paraná Competitivo apresentou um efeito estatisticamente significativo na dinâmica econômica dos municípios receptores dos investimentos. No entanto, no caso do emprego total e da massa salarial, não se constatou efeitos de transbordamentos para os municípios do envoltório.
\end{abstract}

Palavras-chave: Programa Paraná Competitivo. Econometria Espacial. Municípios Paranaenses. Indústria.

The Paraná Competitive Program and its effect on the economic dynamics of the Parana municipalities: a space analysis

\footnotetext{
Abstract

The objective of this work is to analyze the effectiveness of the Competitive Paraná Program in the economic dynamics of the municipalities of Paraná between 2010 and 2014. For this, spatial econometrics was used to verify the effect of the program on the variation of industrial employment, total employment, wage mass and average wage. As a result, there is a process of decentralization of the Paraná industry and Paraná Competitivo

${ }^{1}$ Este artigo faz parte do projeto financiado com recursos da Secretaria de Estado da Ciência, Tecnologia, e Ensino Superior-Seti - Fundo Paraná: "Avaliação da Efetividade e do Efeito Econômico e Social do Programa Paraná Competitivo do Estado do Paraná.
} 
presented a statistically significant effect on the economic dynamics of the municipalities receiving the investments. However, in the case of total employment and wage mass, no overflow effects were found for the municipalities of the wrap.

Keywords: Paraná Competitive Program. Spatial econometrics. Municipalities of Paraná. Industry.

\section{Programa de Parana Competitivo y su efecto sobre la dinámica económica de los municipios paranaenses: un análisis espacial}

\section{Resumen}

El objetivo de este estudio es analizar la eficacia del Programa Paraná Competitivo en la dinámica económica de los municipios de Paraná, entre 2010 y 2014. Para ello, los econometría espacial se utilizó con el fin de verificar el efecto del programa en la variación del empleo industrial, del total del empleo, los salarios y el salario medio. Como corolario, hay un proceso de descentralización de la industria de Paraná y el Paraná Competitivo mostró un efecto estadísticamente significativo sobre la dinámica económica de los receptores de municipios de las inversiones. Sin embargo, en el caso del empleo y los salarios totales, no se encontraron efectos de los derrames a los municipios envuelven.

Palabras clave: Programa de Paraná competitivo. Econometría Espacial. Distritos Municipales. La Industria.

\section{INTRODUÇÃO}

Boa parte das teorias do crescimento econômico tem a industrialização como o principal elemento dinamizador da economia. Nas etapas de crescimento de Rostow (1964), por exemplo, a passagem da sociedade tradicional para a moderna ocorre em que a tecnologia é assimilada e excedentes são aplicados no setor secundário. Da mesma forma, no modelo dual de Lewis (1954), o processo de crescimento econômico se intensifica quando a migração do campo para a cidade se efetiva, induzindo a industrialização e o reinvestimento dos lucros neste setor. Rosenstein-Rodan (1943), numa análise acerca do crescimento equilibrado, também atribuiu à industrialização a responsabilidade por dinamizar o crescimento econômico, em que a realização de um conjunto de investimentos em uma gama de indústrias levaria a economia a um grande impulso. Nesta mesma linha de pensamento, Nurkse (1957) responsabilizava o subdesenvolvimento dos países como resultado do baixo nível de investimento no setor produtivo, gerando um processo retro alimentador.

Essas e outras teorias atribuem o sucesso econômico de uma região à sua industrialização, considerando-a como o motor do crescimento econômico. Os principais argumentos em defesa dessa importância centram-se na hipótese de que esse setor apresenta retorno crescente de escala. Tal afirmação é decorrente do processo cumulativo que se tem quando se efetiva mudanças nesse setor, resultantes especialmente do progresso tecnológico, que é induzido pela expansão da produção (KALDOR, 1970). Ademais, seus efeitos de linkagens também contribuem para esse processo, tanto pela sua alta demanda a montante como pelas suas importantes relações a jusante (HIRSCHMAN, 1958).

A grande questão é que as atividades industriais tendem a se concentrar em poucos espaços, beneficiando-se das economias externas provenientes das 
aglomerações. Quando uma empresa se instala em determinado ponto no espaço, feedbacks positivos podem ser gerados, reforçando as externalidades locais, atraindo novos empreendimentos (KRUGMAN, 1991). Esse processo positivo conduz à formação e ampliação dos aglomerados, decorrentes especialmente da concentração de mão de obra, da presença de infraestrutura, da concentração do setor de serviço, e dos próprios spillovers tecnológicos.

Assim, o ponto onde inicialmente se instala uma unidade produtiva tende a se beneficiar, gerando empregos diretos no setor induzido, como também em outros segmentos encadeados à indústria entrante. Ademais, processa-se um efeito renda, induzindo outras atividades locais, gerando indiretamente a fomentação da economia.

E esses efeitos podem transcender os limites territoriais, beneficiando as regiões vizinhas, por meio da absorção de mão de obra, da compra de matériasprimas, bem como por meio da instalação de empresas satélites neste envoltório. Ou seja, a aglomeração inicial em um ponto no espaço pode gerar benefícios para o seu entorno, formando uma cadeia produtiva importante no que tange à produtividade, emprego e renda.

Por isso, a forma como está distribuída espacialmente o setor secundário é crucial na determinação da dinâmica econômica. No caso do Estado do Paraná, as políticas de industrialização praticadas até a década de 2000 privilegiaram sobretudo a região Metropolitana de Curitiba. Tal região detinha, no início dos anos de 2000 , em torno de $50 \%$ de todo valor adicionado da indústria paranaense, demonstrando o caráter concentrador da atividade produtiva (IPARDES, 2003).

Contudo, a partir de 2011, uma nova política industrial foi implementada no Paraná, denominada "Programa Paraná Competitivo". Suas ações objetivaram atrair novos investimentos, descentralizando regionalmente o setor. Para isso, parcelamento do Imposto sobre Circulação de Mercadorias e Serviços - ICMS incremental e outras medidas que visavam melhorar a infraestrutura, o comércio exterior e a capacitação profissional foram efetuadas. O resultado foi uma atração de mais de 22 milhões de reais entre 2011 e 2014.

Nesse contexto, considerando os argumentos teóricos acerca da importância da indústria para a fomentação do dinamismo econômico de uma região e levando em conta que a partir de 2011 uma nova política de industrialização foi implantada no Estado do Paraná, este artigo tem como objetivo avaliar a efetividade do "Programa Paraná Competitivo" no que se refere à fomentação do emprego industrial, emprego total, salário médio e massa salarial dos municípios paranaenses.

É importante aqui mencionar que o conceito de efetividade adotado no presente trabalho está alinhado com Sano e Filho (2013). Para estes autores, a efetividade de um programa é percebida mediante a avaliação das transformações ocorridas a partir de uma ação realizada. Tal conceito se diferencia de outros dois muito utilizados em avaliações de políticas públicas: eficiência e eficácia. A avaliação da eficácia se dá a partir da relação das metas alcançadas e das metas pretendidas, e a eficiência é o alcance dos objetivos propostos pela política pública com menos recursos.

Assim, para analisar a efetividade se entende que ação realizada é o “Programa Paraná Competitivo" que, como descrito anteriormente, tem por 
objetivo atrair investimentos para o setor produtivo paranaense, $e$ as transformações ocorridas a partir dessa ação é a geração de empregos e renda nos municípios do Estado do Paraná. Com a metodologia empregada no presente trabalho (econometria espacial), será possível avaliar os efeitos do programa não apenas nos municípios que receberam os investimentos, mas também os efeitos que tais investimentos tiveram na geração de trabalho e renda nos municípios vizinhos.

Este trabalho está composto de cinco seções, incluindo esta. Na segunda, tem-se a evolução da industrialização do Paraná entre 2010 e 2014. Na sequência, descreve-se a metodologia utilizada no trabalho. Na quarta seção, realiza-se uma análise exploratória dos dados espaciais, bem como avalia-se a efetividade do Programa Paraná Competitivo. Por fim, a seção cinco aborda as considerações finais.

\section{O PROGRAMA PARANÁ COMPETITIVO E A INDUSTRIZALIZAÇÃO DOS MUNICÍPIOS DO PARANÁ ENTRE 2011-2014}

Em 2011, uma nova política industrial foi implementada no Paraná. Trata-se do Programa Paraná Competitivo, cujo principal objetivo consiste na atração de novos investimentos, promovendo a descentralização regional do setor produtivo paranaense. Tem como mecanismo de atração o parcelamento do ICMS incremental, além de propor medidas para o melhoramento da infraestrutura, do comércio exterior, da capacitação profissional, dentre outras. No período entre fevereiro de 2011 e dezembro de 2014, o programa de industrialização contabilizou a atração de mais de $R \$ 22$ bilhões em investimentos industriais privados, nacionais e multinacionais, distribuído em 58 municípios paranaenses (Figura 1). 
Figura 1. Municípios beneficiados com investimentos do Paraná Competitivo (a) e valores recebidos por cada município do Paraná (b) - milhões de R\$ - 2011 a 2014

(a)

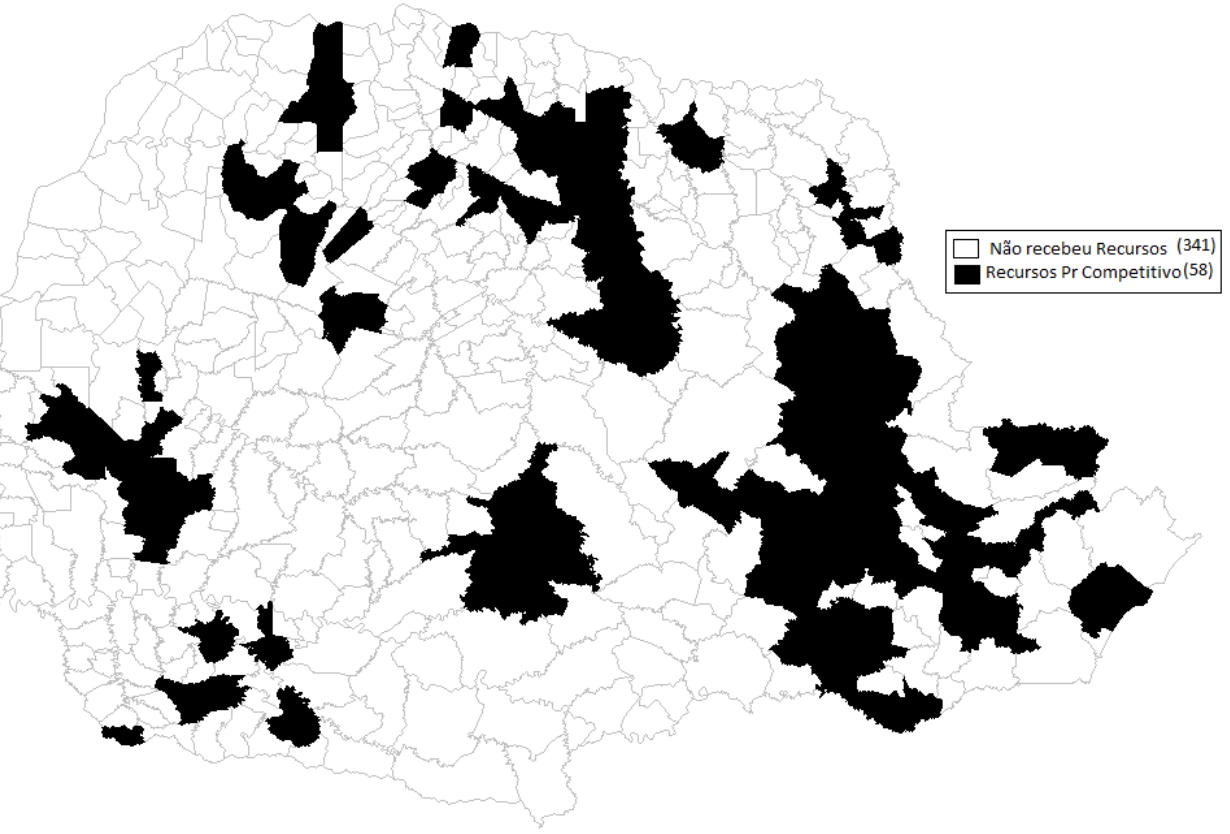

(b)

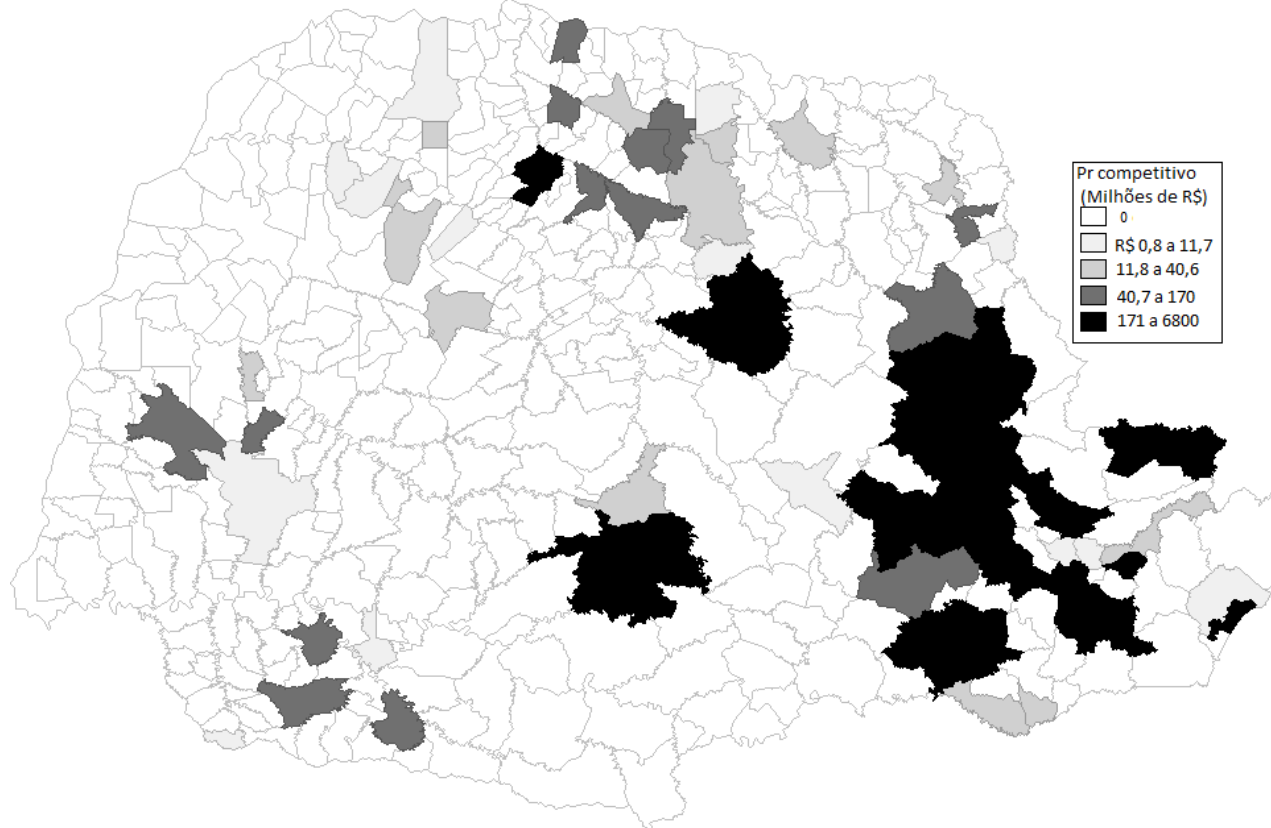

Fonte: Agência Paraná de Desenvolvimento.

Visualmente, é perceptível a concentração espacial destes recursos em alguns pontos do Paraná. Do total de municípios beneficiados, $19 \%$ estavam localizados na Região Metropolitana de Curitiba - RMC, $14 \%$ na região dos Campos Gerais e os demais espalhados ao longo do interior do Estado. Embora ainda 
centrado no eixo que vai da região Metropolitana de Curitiba aos Campos Gerais, esses investimentos privilegiaram especialmente municípios com uma estrutura industrial embrionária.

Em 2010, tinha-se 362 municípios com participação do emprego industrial inferior a 50\% do emprego total; destes, 48 municípios foram contemplados com investimentos do Paraná Competitivo. Ou seja, dos 58 municípios que participaram do Programa, $83 \%$ eram municípios que não tinham a indústria como principal indutora do emprego local. Nesse sentido, por mais que muitos municípios beneficiados estejam localizados próximos à capital paranaense, tem-se uma tendência de descentralização da indústria - via Programa Paraná Competitivo para os municípios nos quais tal setor não era tão dinâmico.

Ademais, esse espraiamento da indústria torna-se relevante para o próprio processo de formação de aglomerados que poderá se ter no futuro. Com efeito, segundo a literatura, a localização industrial inicial em novos pontos do espaço pode gerar, ex post, a formação de aglomerados produtivos pelos diferentes encadeamentos industriais que tendem a surgir, além de fomentar outras atividades nos demais setores (comércio, serviço e a própria agricultura). Ao mesmo tempo, essa formação de aglomerados conduz à formação de externalidades - como concentração de mão de obra qualificada, difusão tecnológica, economias de escala, etc - que induzem posteriormente a intensificação das atividades produtivas deste espaço. É nesse sentido que, teoricamente, defende-se que uma melhor distribuição da indústria ao longo do espaço - como é o caso paranaense (Figura 2b) - poderá contribuir, no médio e longo prazo, para uma descentralização da atividade econômica.

Conforme aborda Krugman (1991), a decisão de localização da indústria não se dá ao acaso. Leva-se em conta a proximidade com o mercado consumidor, com os fornecedores, a infraestrutura existente, a disponibilidade de mão de obra, dentre outros elementos decisivos para a eficiência das empresas. Algumas regiões naturalmente apresentam tais atrativos, ocorrendo a concentração industrial de forma espontânea, sendo influenciadas pelas condições físicas da região (como clima, produtividade do solo, etc.), pela abundância de insumos (como a presença de mão de obra qualificada, etc.), ou devido às questões logísticas (como fácil acesso por terra e/ou mar). Contudo, as aglomerações também podem ser induzidas por meio de políticas públicas de desenvolvimento regional (como isenção de impostos), que acabam incentivando as firmas a se instalarem em determinadas localidades. E esse é o caso do Programa Paraná Competitivo 
Figura 2. Participação (\%) no emprego industrial em 2010 (a) e variação absoluta do emprego industrial entre 2010-2014 (b) - municípios do Paraná

(a)

(b)

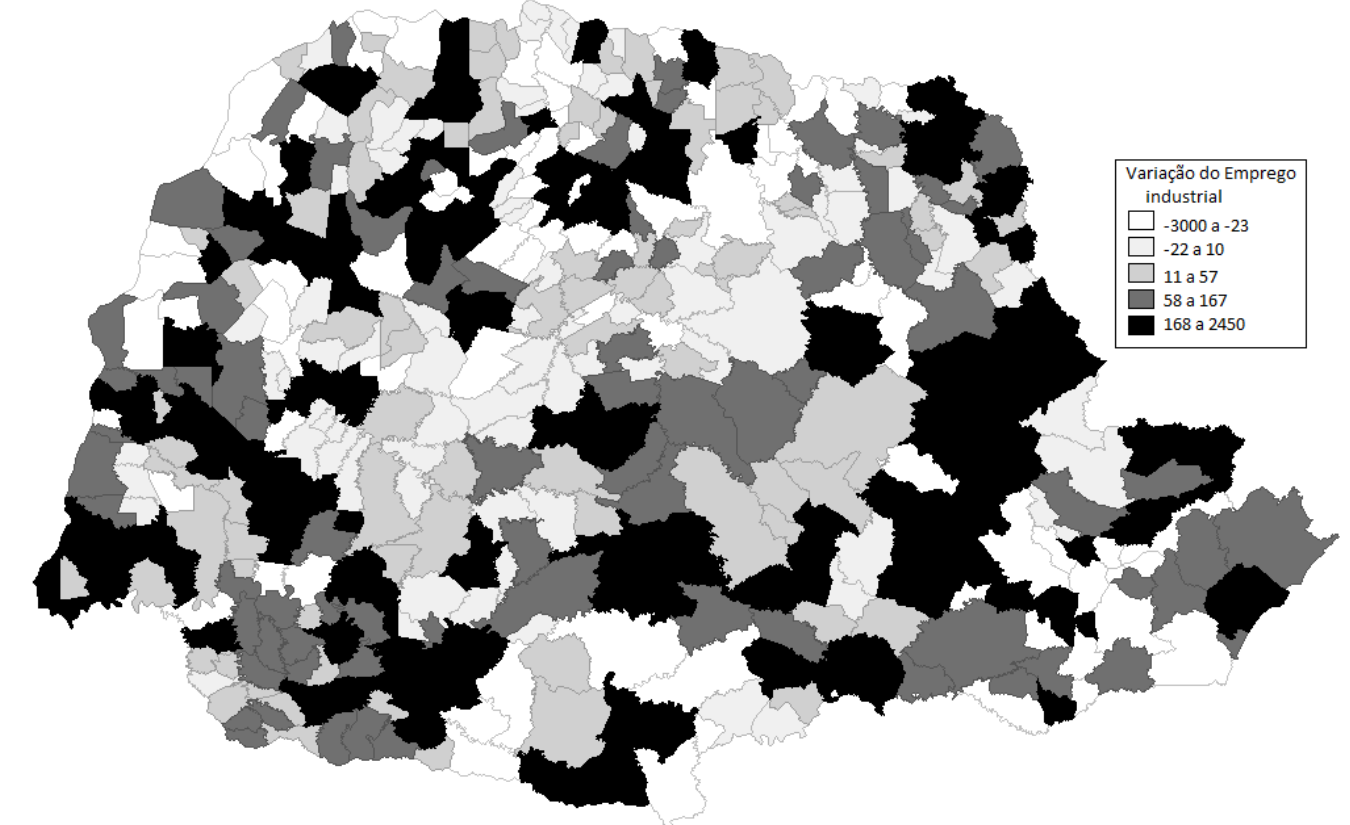

Fonte: Rais, com dados organizados pela pesquisa.

Na figura 2(a), observa-se que, em 2010, a distribuição espacial da indústria era bastante desigual no Paraná, sendo poucos municípios responsáveis pela maior parte dos empregos industriais paranaenses. No entanto, a criação de novos postos de trabalho entre os anos de 2010 e 2014 (figura 2b) não favoreceu exclusivamente esses pontos nos quais já se tinha um dinamismo maior da industrialização, pois, em 
muitos casos, beneficiou também aqueles municípios mais carentes de industrialização no período inicial. Tal resultado pode ser derivado do próprio Programa Paraná Competitivo, que induziu a industrialização para os municípios que não tinham, ex ante, um forte dinamismo deste setor. Esse é o caso dos municípios de Adrianópolis, Pontal do Paraná, Ipiranga, Jesuítas, Tamboara, Ortigueira, dentre outros.

No gráfico 1, subdividiu-se os municípios receptores dos investimentos do Paraná Competitivo, diferenciando os que estão localizados no interior do Estado. De forma geral, o período de 2010 a 2014 apresentou oscilação na variação dos postos de trabalho criados, revelando um desempenho melhor para os municípios que receberam recursos do programa, especialmente os que estão localizados no interior do Paraná. Ademais, destaca-se que, a partir de 2012, a variação absoluta de emprego nos municípios que receberam recursos do Programa Paraná Competitivo ficou mais acelerada do que a dos municípios que não foram comtemplados no programa.

Talvez tal fato esteja associado à maturação dos investimentos, os quais não aconteceram exatamente no momento que foram anunciados, levando um período de tempo para se efetivar. Isso sinaliza para um dinamismo ainda maior nos próximos anos, tendo em vista que muitos investimentos foram anunciados recentemente, não se efetivando por completo ainda.

\section{Gráfico 1.- Variação absoluta do emprego industrial nos municípios paranaenses- 2011 a} 2014

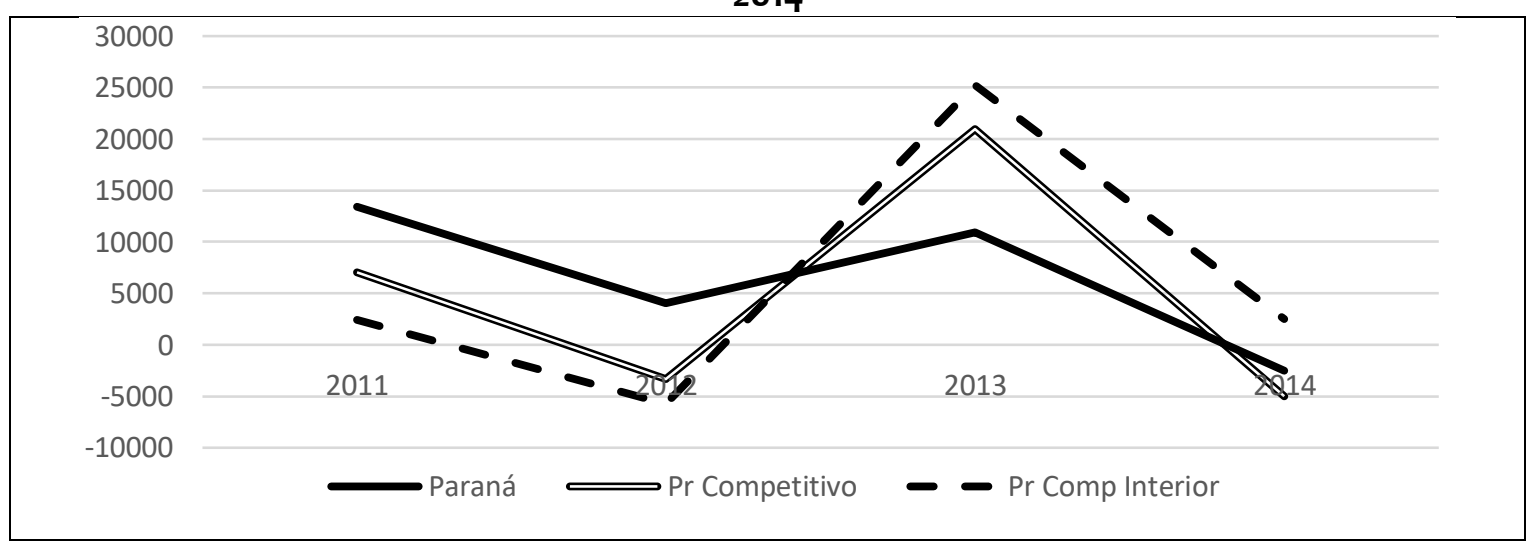

Fonte: Rais, com os dados organizados pela Pesquisa.

Nota: Paraná refere-se aos municípios que não receberam financiamento do Paraná Competitivo; $\mathrm{Pr}$ Competitivo são todos os que receberam financiamento do Programa; PrComp Interior são os que receberam e localizam-se no interior do Estado.

Um adendo deve ser feito em relação ao período que se está sendo analisando. O Paraná Competitivo foi implementado num período de crise econômica do País. Nesse escopo, é natural uma perda de dinamismo especialmente daqueles municípios que já tinham uma maior industrialização, refletindo os efeitos da crise. Nesse sentido, mesmo com ações do Paraná Competitivo induzindo a vinda de novos investimentos ou ampliação de plantas já existentes, muitas firmas que já existiam podem ter perdido dinamismo. Isso explica a fomentação maior do emprego industrial especialmente para os municípios do 
interior, que, em geral, não tinham concentração produtiva, e, potencialmente, perderam menos com a crise por ainda não terem uma aglomeração formada.

Em termos absolutos, o montante de emprego industrial praticamente não se alterou nos municípios participantes do Paraná Competitivo que se localizam na RMC; mas para aqueles que estão no interior, houve uma inserção elevada (Gráfico 2). É importante destacar que são 26 municípios que formam a RMC e 11 deles participaram do Paraná Competitivo, ressaltando que estes últimos detinham $27 \%$ do emprego da indústria em 2014 e representavam 3\% dos municípios do Estado. Portanto, parte desses municípios já tinha uma base industrial formada e possivelmente a crise econômica teve um impacto maior no seu dinamismo econômico.

Gráfico 2 - Variação absoluta do emprego industrial nos municípios paranaenses 2010 e 2014

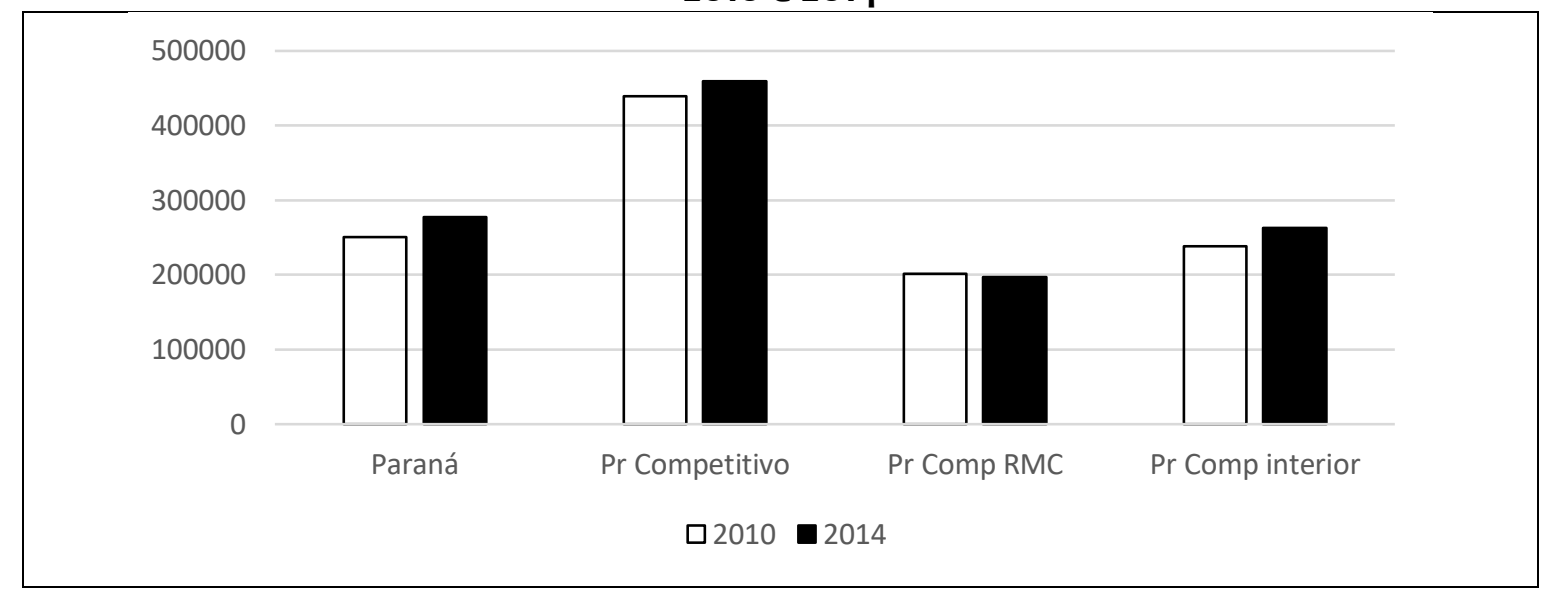

Fonte: Rais, com os dados organizados pela Pesquisa.

Nota: Paraná refere-se aos municípios que não receberam financiamento do Paraná Competitivo; $\mathrm{Pr}$ Competitivo são todos os que receberam financiamento do Programa; PrComp RMC são os que receberam e localizam-se na RMC e; PrComp Interior são os que receberam e localizam-se no interior do Estado.

Diferentemente do emprego, os municípios que foram beneficiados pelo Paraná Competitivo e que se localizam na RMC, bem como os que estão no interior do Estado, conseguiram ter um incremento importante no valor adicionado da indústria; já o grupo dos municípios que não participaram do Paraná Competitivo tiveram perdas entre 2010 e 2013 (Gráfico 3). De certa forma, isso sinaliza para a importância do programa na garantia da competitividade da indústria, a qual não necessariamente elevou o emprego mas contribuiu para o aumento da produção, indicando ganhos de produtividade. 
Gráfico 3. Valor Adicionado da Industria nos municípios paranaenses - 2010 e 2013 (Mil reais, $2010=$ 100, Deflator Implícito da Indústria)

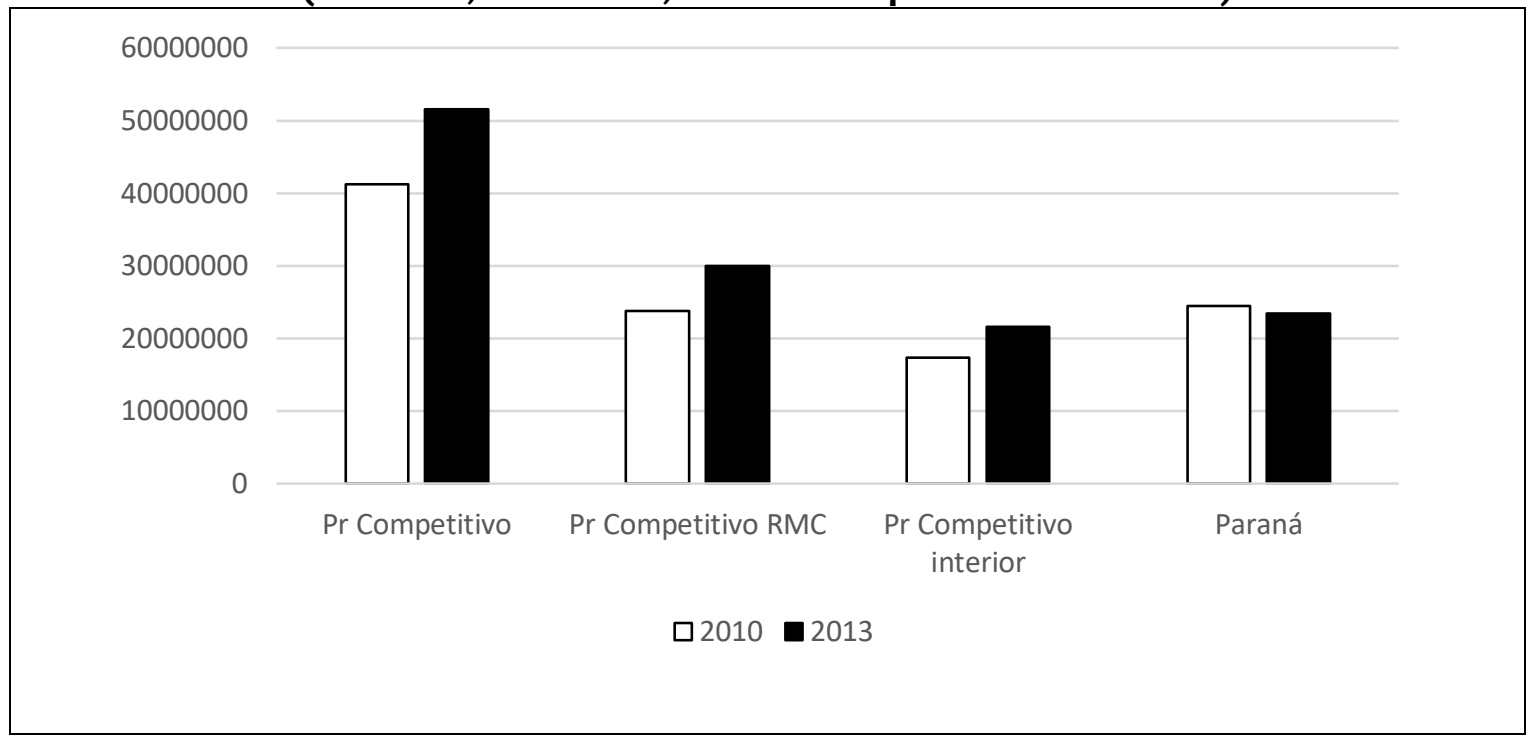

Fonte: Ipardes, organizado pela pesquisa.

Nota: Paraná refere-se aos municípios que não receberam financiamento do Paraná Competitivo; $\mathrm{Pr}$ Competitivo são todos os que receberam financiamento do Programa; Pr Competitivo RMC são os que receberam e localizam-se na RMC e; Pr Competitivo Interior, são os que receberam e localizamse no interior do Estado.

\section{METODOLOGIA}

\subsection{Análise exploratória de dados espaciais}

Antes de estimar o modelo econométrico acerca dos efeitos do Programa Paraná Competitivo na geração de emprego e renda nos municípios paranaenses, realizou-se uma breve análise exploratória dos dados espaciais (doravante AEDE), baseada na correlação espacial bivariada (estatística I de Moran bivariada).

Para implementar essa análise, faz-se necessário a adoção de uma matriz de ponderação espacial (W). Conforme Almeida (2012), essa é uma matriz quadrada de ordem $n$ por $n$, cujos elementos denotam o grau de conexão espacial entre os municípios em análise, seguindo algum critério de proximidade. Esse critério, por sua vez, baseou-se na contiguidade (com convenção do tipo torre, rainha e do vizinho mais próximo), tendo como pressuposto que as regiões contíguas possuem uma interação mais forte do que aquelas não contíguas.

Essa interação pode tanto estimular o espraiamento como a repulsão da variável selecionada (no caso desta pesquisa, variação do emprego industrial, emprego total, massa salarial e salário médio). Assim, o elemento $w_{i j}$ da matriz de ponderação espacial $(W)$ teve valor igual a 1 quando dois municípios eram contíguos, e o em caso contrário.

$\mathrm{Na}$ implementação da AEDE foram utilizados os testes da autocorrelação espacial global num contexto bivariado, procurando descobrir se os valores de uma variável observada (Investimentos do Programa Paraná Competitivo) em um determinado município tiveram uma relação sistemática com os valores de uma 
outra variável observada (variação do emprego industrial, do emprego total, da massa salarial e do salário médio) nos municípios vizinhos.

Em termos formais, o cálculo da estatística I de Moran para duas variáveis diferentes, y e $x$ foi realizado mediante a equação 01. Valores positivos e negativos do I de Moran bivariado denotam concentração e dispersão espaciais, respectivamente.

$$
\mathrm{I}^{\mathrm{yx}}=\frac{\mathrm{n}}{\sum_{\mathrm{i}} \sum_{\mathrm{j}} \mathrm{w}_{\mathrm{ij}}} \frac{\sum_{\mathrm{i}} \sum_{\mathrm{j}}\left(\mathrm{x}_{\mathrm{i}}-\overline{\mathrm{x}}\right) \mathrm{w}_{\mathrm{ij}}\left(\mathrm{y}_{\mathrm{i}}-\overline{\mathrm{y}}\right)}{\sum_{\mathrm{i}}\left(\mathrm{x}_{\mathrm{i}}-\overline{\mathrm{x}}\right)^{2}}
$$

Com essa primeira análise exploratória, foi possível verificar o grau de relacionamento das variáveis analisadas.

\subsection{Especificação dos modelos empíricos}

O principal objetivo deste trabalho é testar o efeito do Programa Paraná Competitivo na geração de emprego e renda nos municípios paranaenses. Para tanto, selecionou-se como variáveis dependentes do modelo empírico as seguintes variáveis: emprego industrial, emprego total, massa salarial e salário médio dos municípios paranaenses².

Inicialmente, testou-se os fatores determinantes da variação do empego industrial (entre 2010 e 2014) nos municípios paranaenses. Como variáveis explicativas, teve-se: distância da capital; dummy para captar a participação da indústria da alta e/ou média alta tecnologia no emprego total, dando um (01) quando o município tem qualquer participação da alta e/ou média alta tecnologia no emprego industrial em 2010 e zero (o) em caso contrário33 (Dummy alta/média tecnologia); Soma dos montantes investidos do Paraná Competitivo entre 2010 e 2014 (Pr Competitivo); uma dummy de interação entre ser da RMC e participar do programa, recebendo valor igual a "um" e "zero" caso contrário (Dummy RMC * Pr Com); Emprego industrial inicial (2010) e; produtividade inicial (2010).

No caso deste último, mensurou-se o Índice de Desenvolvimento da Indústria - IDI, considerando três indicadores: escolaridade média dos trabalhadores da indústria, salários médios ${ }^{4}$ do setor secundário e percentual de ocupações técnicas e científicas da indústria, conforme metodologia apresentada por Saboia e Kubrusli (2008). O peso para cada indicador foi determinado por meio da análise de componentes principais 5 .

\footnotetext{
2 Para mensurar a variação do emprego, da massa salarial e do salário médio, utilizou-se os dados da Rais (Relação Anual de Informações Sociais), fornecidas pelo Ministério do Trabalho.

3 A classificação para a alta e média alta tecnologia seguiu a metodologia aplicada por Furtado e Carvalho (2005).

4 Deflacionado pelo INPC.

5 Ressalta-se que na determinação dos pesos não foi utilizado os valores dos componentes em si, mas os resultados anteriores à análise de componentes principais, com as seguintes etapas:

i) Obtenção dos autovalores da matriz de correlação, por meio da análise do componente principal (ACP). Em cada um deles tem-se a explicação na variância, destacando que a soma dos betas corresponde à variância total dos componentes e, dessa forma, à variância total dos indicadores selecionados.

ii) Recálculo dos autovalores da matriz de correlação, buscando encontrar a participação relativa de cada um dos elementos em cada um dos componentes. Primeiramente cada autovalor é adotado em módulo e dividido pelo somatório dos autovalores absolutos de seu componente, obtendo sua participação no componente correspondente.

iii) A construção dos pesos é dada por meio da multiplicação da participação relativa dos indicadores nos componentes com a variação caracterizada pelo componente. A soma fornece o peso de cada indicador.
} 


$$
\mathrm{IDI}_{\mathrm{i}, \mathrm{t}}=\emptyset_{1}\left(\mathrm{ESC}_{\mathrm{i}, \mathrm{t}}\right)+\emptyset_{2}\left(\mathrm{SAL}_{\mathrm{i}, \mathrm{t}}\right)+\emptyset_{3}\left(\mathrm{OT}_{\mathrm{i}, \mathrm{t}}\right)
$$

Em que: IDI refere-se ao índice de desenvolvimento da indústria; ESC é a escolaridade média da indústria; SAL refere-se ao salário médio; OT é o percentual de ocupações técnicas e científicas; i é o município; $t$ é o tempo; $\phi$ refere-se ao peso.

IsSo posto, o primeiro modelo estimado se referiu ao efeito dessas variáveis supracitadas sobre a variação do emprego industrial $\left(\Delta \mathrm{EI}_{\mathrm{i}}^{(10 / 14)}\right)$ dos municípios paranaenses:

$$
\begin{aligned}
& \Delta \mathrm{EI}_{\mathrm{i}}^{10 / 14}=\beta_{0}+\beta_{1} \beta_{1} \text { Emprego industrial inicial }_{\mathrm{i}}+\beta_{2} \text { Distância da Capital }_{\mathrm{i}_{\mathrm{i}}} \\
& +\beta_{2} \text { Produtividade inicial }_{i}+\beta_{3} \text { Dummy alta/média tecnologia }_{i}
\end{aligned}
$$

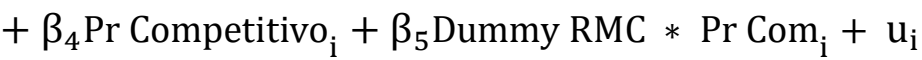

Já o segundo modelo especificado (04) objetivou identificar o efeito do Programa Paraná Competitivo na variação do emprego total entre 2010 e 2014 $\left(\Delta \mathrm{ET}_{\mathrm{i}}^{(10 / 14)}\right)$.

$$
\begin{aligned}
& \Delta \mathrm{ET}_{\mathrm{i}}^{10 / 14}=\beta_{0}+\beta_{1} \beta_{1} \text { Emprego total inicial }_{\mathrm{i}}+\beta_{2} \text { Distância da Capital }_{\mathrm{i}_{\mathrm{i}}}
\end{aligned}
$$

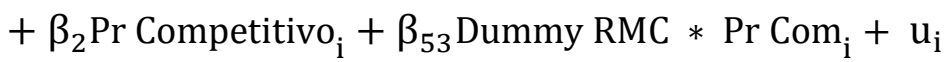

O terceiro e quarto modelo se referem à renda do trabalho formal que é gerada. O terceiro buscou identificar o impacto do Programa Paraná Competitivo na variação da massa salarial (05), representada por $\Delta \mathrm{MS}_{\mathrm{i}}^{(10 / 14)}$, e o último modelo mediu o efeito do programa na variação da média salarial, representado por $\Delta \mathrm{MD}_{\mathrm{i}}^{(10 / 14)}(06)$.

$$
\begin{aligned}
& \Delta \mathrm{MS}_{\mathrm{i}}^{10 / 14}=\beta_{0}+\beta_{1} \text { Massa Salarial inicial }_{\mathrm{i}}+\beta_{2} \text { variação salário médio }_{\mathrm{i}}
\end{aligned}
$$

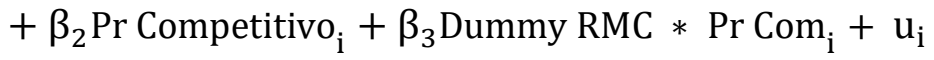

$$
\begin{aligned}
& \Delta \mathrm{MD}_{\mathrm{i}}^{10 / 14}=\beta_{0}+\beta_{1} \text { Média Salarial inicial }_{\mathrm{i}}+\beta_{2} \Delta \text { Massa salarial } i_{\mathrm{i}} \\
& +\beta_{3} \text { Dummy alta/média tecnologia }_{i}+\beta_{4} \text { Pr Competitivo }_{i} \\
& +\beta_{5} \text { Dummy RMC } * \operatorname{Pr} \operatorname{Com}_{\mathrm{i}}+\mathrm{u}_{\mathrm{i}}
\end{aligned}
$$

Destaca-se que os parâmetros dos modelos foram estimados com base na econometria espacial. Nesse aspecto, a utilização das técnicas da econometria espacial é de suma importância, pois com ela foi possível identificar se os investimentos atraídos pelo Programa Paraná Competitivo ficaram restritos aos municípios participantes do programa, ou se, além disso, tiveram efeitos sobre a geração de emprego e renda dos municípios vizinhos.

Para utilizar essa técnica, o primeiro passo é a decisão sobre o melhor modelo espacial: Modelo de defasagem espacial - SAR ou Modelo de erro autorregressivo espacial - SEM. Para detectar a autocorrelação espacial e definir o

A soma dos pesos $\phi_{1}+\phi_{2}+\phi_{3}$ é igual a "um" e, assim, cria-se uma combinação linear dos indicadores propriamente padronizados. 
modelo espacial mais apropriado, considerou-se os testes do tipo Multiplicador de Lagrange - ML. O teste ML $\rho$ observa a defasagem espacial (hipótese nula de $H_{0}: \rho$ $=0$ ), enquanto que o teste $M L \lambda$ observa a autocorrelação espacial no erro (hipótese nula $\left.H_{0}=\lambda=0\right)$.

Silva et al. (2013) apontam algumas etapas a fim de identificar o modelo econométrico mais adequado: i) estima-se o modelo pelo MQO; ii) através das estatísticas ML $\rho$ e $M L \lambda$, testa-se a presença de autocorrelação espacial; iii) caso ambos os testes forem não significativos, o modelo não demonstra autocorrelação espacial; iv) caso ambos os testes forem significativos, é necessário o cálculo de versões robustas destes testes e estimativa do modelo mais significante; v) se apenas um dos testes for significativo, este é o modelo mais adequado. Considerando os resultados do ML $\rho$ e $M L \lambda$ (reportados nas Tabelas 2, 3, 4 e 5), o modelo econométrico mais indicado para (04) e (05) é o SAR, enquanto que, para (03) e (06), é o SEM.

Em termos gerais, o modelo SAR, pode ser expresso como:

$$
\mathrm{y}=\rho \mathrm{Wy}+\mathrm{X} \beta+\varepsilon
$$

Em que y é a variável dependente; $\rho$ é o coeficiente autorregressivo espacial; Wy é um vetor $\mathrm{nx} 1$ de defasagens espaciais para a variável dependente; $X$ é a matriz das variáveis explicativas; $\beta$ é um vetor de parâmetros e $\varepsilon$ é o termo erro.

Já o modelo SEM pode ser descrito como:

$$
\begin{gathered}
y=X \beta+\xi \\
\xi=\lambda W \xi+\varepsilon
\end{gathered}
$$

Em que o parâmetro $\lambda$ é o erro autorregressivo espacial que acompanha a defasagem $W \xi$. Nesse modelo, a dependência espacial se revela no termo de erro, enfatizando que os erros relacionados com qualquer observação são uma média dos erros nas regiões do envoltório, acrescentados de um componente aleatório. Assim, o termo de erro do modelo SEM indica que os efeitos sobre a variável dependente não resultam apenas do choque aleatório $(\varepsilon)$, mas também do transbordamento de choques provenientes de outras regiões vizinhas.

Ademais, além de incorporar a ideia do transbordamento por meio da defasagem das variáveis explicativas (WX), apresenta-se em (09) a inclusão da variável dependente defasada (modelo de Durbin espacial - SDM).

$$
y=\pi_{1} W y+\pi_{2} X+\pi_{3} W X+\varepsilon
$$

Modelo alternativo refere-se ao Durbin espacial do erro - SDEM, incorporando componentes espaciais de alcance local que se manifesta nas variáveis explicativas exógenas e componentes espaciais que afetam o termo de erro (10).

$$
y=X \beta+W X \tau+\xi
$$


O Programa Paraná Competitivo e seu efeito na dinâmica econômica dos municípios paranaenses:

$$
\xi=\lambda W \xi+\varepsilon
$$

É importante destacar que para decidir entre os modelos SDM e SDEM foram adotados os mesmo procedimentos descritos anteriormente, baseados nos testes do tipo Multiplicador de Lagrange.

Por fim, ressalta-se que todas as estimativas que apresentaram problemas econométricos (heterocedasticidade ou normalidade) foram reestimadas, com a correção dos referidos problemas. Para controlar a heterocedasticidade, utilizou-se a correção de heterocedasticidade pela matriz de White. No caso da ausência de normalidade nos erros, usou-se o método de momentos generalizados, pois prescinde da hipótese da normalidade dos erros (ALMEIDA, 2012) ${ }^{6}$.

\section{PROGRAMA PARANÁ COMPETITIVO E A DINÂMICA ECONÔMICA DOS MUNICÍPIOS PARANAENSES}

\subsection{Análise preliminar}

A forma como estão distribuídas as atividades produtivas espacialmente interfere na dinâmica econômica de toda a região. Quando uma empresa se instala em determinado ponto do espaço, feedbacks positivos podem ser gerados, reforçando as externalidades locais, atraindo novos empreendimentos (KRUGMAN, 1991). Esse processo positivo conduz a formação e ampliação dos aglomerados, decorrentes especialmente da concentração de mão de obra, da presença de infraestrutura, da concentração do setor de serviço, e dos próprios spillovers tecnológicos.

Isso significa que, naqueles espaços nos quais inicialmente se instalou uma unidade produtiva, processos cumulativos ocorrem, beneficiando o município, gerando empregos diretos no setor induzido, como também em outros segmentos encadeados à indústria entrante. Portanto, gera-se um efeito renda, induzindo a outras atividades locais, promovendo indiretamente a fomentação daquela economia.

No entanto, alguns autores, como Hirschamn (1958), inferem que estes efeitos podem transcender os limites territoriais, beneficiando as regiões vizinhas, por meio da absorção de mão de obra, da compra de matérias-primas, bem como por meio da instalação de empresas satélites neste envoltório. Ou seja, a aglomeração inicial em um ponto do espaço pode gerar benefícios para o seu entorno, formando uma cadeia produtiva importante no que tange à produtividade, emprego e renda.

A expectativa é que outros espaços regionais se beneficiem, ex post, dessas economias externas, desenvolvendo seus parques produtivos e elevando a produtividade da indústria. Saboia e Kubrusly (2008) argumentam acerca da importância dessa descentralização no desenvolvimento industrial especialmente pelos transbordamentos que as indústrias entrantes e/ou nascentes trazem para a região, como mão de obra qualificada, spillovers tecnológicos, otimização dos

6 Os testes de normalidade (Jarque-Bera) e de Heterocedasticidade (Breuch-Pagan) estão apresentados nas tabelas 2, 3, 4, e 5 . 
custos pela proximidade com seus fornecedores, infraestrutura instalada, dentre outros fatores.

Nesse sentido, essa variação positiva do emprego industrial entre 2010-2014 (figura 2b) em muitos municípios paranaenses que não tinham uma dinâmica importante na indústria no ano inicial (figura 2a) pode ter influenciado a formação de aglomerados produtivos nestes municípios, assim como pode ter impactado nos municípios vizinhos. Ao mesmo tempo, essa variação do emprego pode estar ligada, em alguma magnitude, com o Programa Paraná Competitivo.

Com efeito, na Tabela 1, apresenta-se exatamente essa correlação espacial entre os municípios que receberam investimentos do Programa e a variação do emprego industrial dos municípios do envoltório, observando um efeito positivo e estatisticamente significativo. Ou seja, aqueles municípios que receberam investimentos do Paraná Competitivo tenderam a estar espacialmente rodeados por municípios com variações absolutas de empregos mais elevada (e vice-versa). Portanto, é possível que o Programa esteja contribuindo para o processo de descentralização do emprego industrial ao longo do Paraná.

Tabela 1. Coeficiente I de Moran bivariado entre municípios que receberam investimentos do Programa Paraná Competitivo e variáveis selecionadas municípios do Paraná - 2010/2014

\begin{tabular}{c|c|c|c|c|c}
\hline \multirow{2}{*}{ Variáveis selecionadas } & \multicolumn{6}{|c}{ Convenções } \\
\cline { 2 - 6 } & Rainha & Torre & 4 viz & $5 \mathrm{viz}$ & $6 \mathrm{viz}$ \\
\hline Var. Emprego Industrial & $0,09^{*}$ & $0,08^{*}$ & $0,07^{*}$ & $0,07^{*}$ & $0,05^{*}$ \\
Var. Emprego Total & $0,09^{*}$ & $0,10^{*}$ & $0,08^{*}$ & $0,08^{*}$ & $0,07^{*}$ \\
Var. Salário médio & $0,10^{*}$ & $0,10^{*}$ & $0,09^{*}$ & $0,09^{*}$ & $0,07^{*}$ \\
Var. Massa salarial & 0,02 & 0,001 & 0,03 & 0,03 & 0,03 \\
\hline
\end{tabular}

Fonte: Estimado pelos autores por meio do software Geoda.

Nota: A pseudo-significância empírica baseada em 999 permutações aleatórias; * e ** significativo a um nível de significância de 5\% e 10\%, respectivamente.

Além disso, outras variáveis selecionadas também apresentaram um coeficiente I de Moran bivariado positivo e estatisticamente significativo. Este foi o caso da variação do emprego total e do salário médio. É importante destacar que quando se tem uma aglomeração industrial - induzida ou formada naturalmente seus benefícios (em termos economias de escala, spillovers tecnológicos, oferta de serviços/infraestrutura, mão de obra especializada, etc) não se restringem apenas às firmas aglomeradas.

Jacobs (1969) aponta que esses efeitos são bem mais abrangentes, resultantes da diversidade de atividades econômicas presentes no interior de um município, as quais são denominadas de economias de urbanização. Dessa forma, considera que a diversificação de bens, serviços e tecnologias de um centro urbano possibilita a criação de uma atmosfera propícia para a troca de experiências e informações, constituindo o alicerce do desenvolvimento de uma determinada região. 
Ou seja, uma política de indução da industrialização não necessariamente vai beneficiar apenas o setor secundário, gerando externalidades para os demais segmentos, induzindo a uma dinâmica maior da economia como um todo. Isso se reflete na formação de mais postos de trabalho, mais renda, e numa eficiência maior das atividades ali desenvolvidas.

Por isso, a expectativa que, em parte, foi corroborada pelos resultados da tabela 1 é que o Programa Paraná Competitivo também afeta a formação de empregos total e a própria média salarial, mas não só do município beneficiado pelo programa, afetando, em alguma medida, os municípios do seu envoltório. Portanto, impulsos dados à industrialização tendem a beneficiar não somente o município que atraiu tais recursos, mas também seu envoltório, atingindo não só a atividade secundária, mas outros segmentos encadeados a ele.

$\mathrm{Na}$ Figura 3, tem-se a distribuição espacial da variação do emprego total, da massa salarial, do salário médio e do emprego industrial, que apresentam uma tendência próxima à que se teve na variação do emprego industrial (figura $3 \mathrm{~d}$ ), estando as maiores alterações espalhadas ao longo de todo o Estado, e não apenas naqueles municípios que inicialmente eram mais dinâmicos (figura 2a).

Ademais, quando se compara as figuras 3(a), (b), (c) e (d) com a figura 3(e), percebe-se que boa parte dos municípios que receberam recursos do Paraná Competitivo conseguiram variações do emprego total, massa salarial, do salário médio, e do emprego industrial, num montante mais elevado, tendendo a mostrar certa correlação entre os investimentos do programa e o dinamismo destas variáveis.

Figura 3 - Variação absoluta do emprego total (a), da massa salarial (b), do salário médio (c), do emprego industrial (d) entre 2010-2014 e municípios que receberam investimentos do Paraná Competitivo (e) - municípios do Paraná

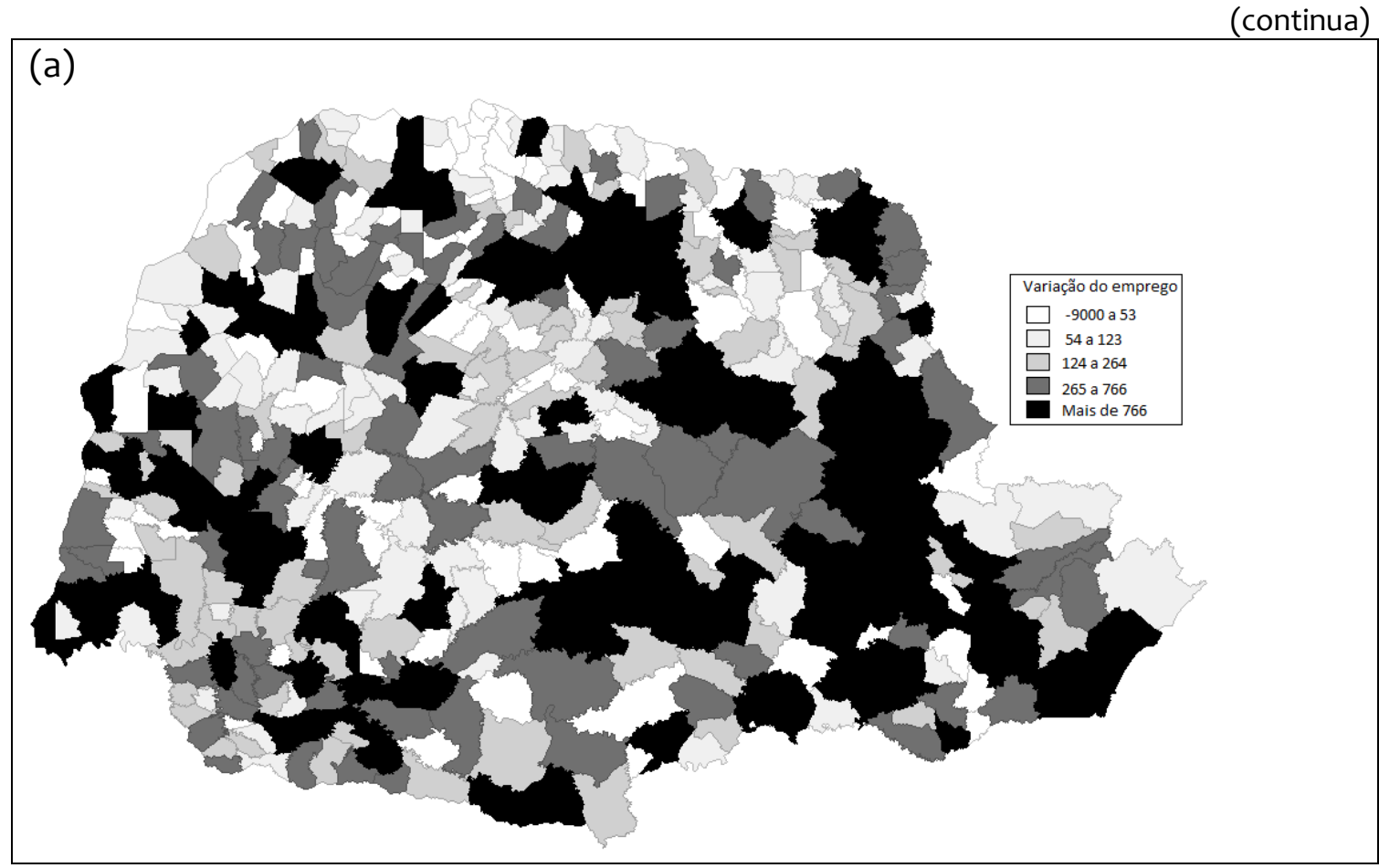


Figura 3 - Variação absoluta do emprego total (a), da massa salarial (b), do salário médio (c), do emprego industrial (d) entre 2010-2014 e municípios que receberam investimentos do Paraná Competitivo (e) - municípios do Paraná

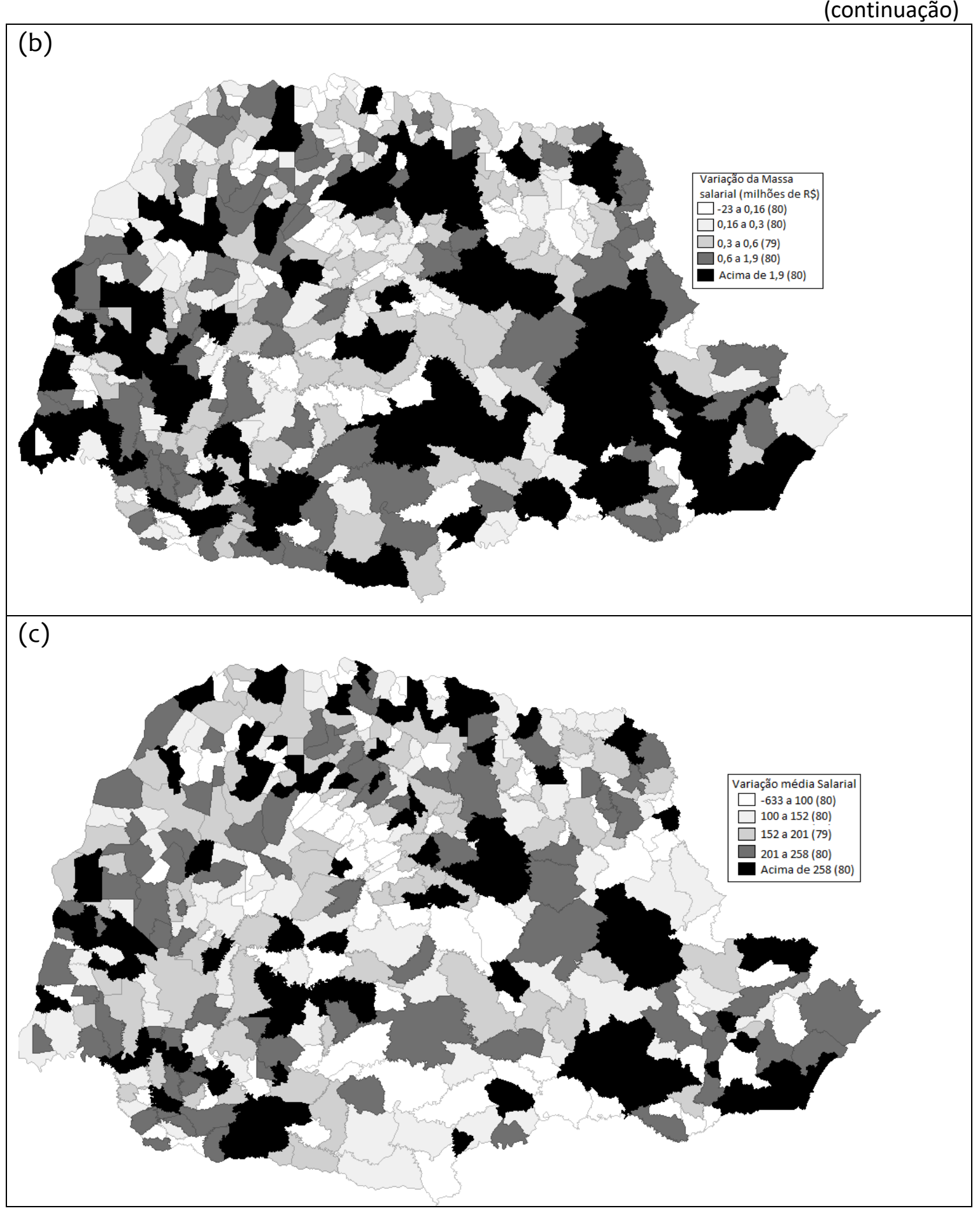


Figura 3 - Variação absoluta do emprego total (a), da massa salarial (b), do salário médio (c), do emprego industrial (d) entre 2010-2014 e municípios que receberam investimentos do Paraná Competitivo (e) - municípios do Paraná

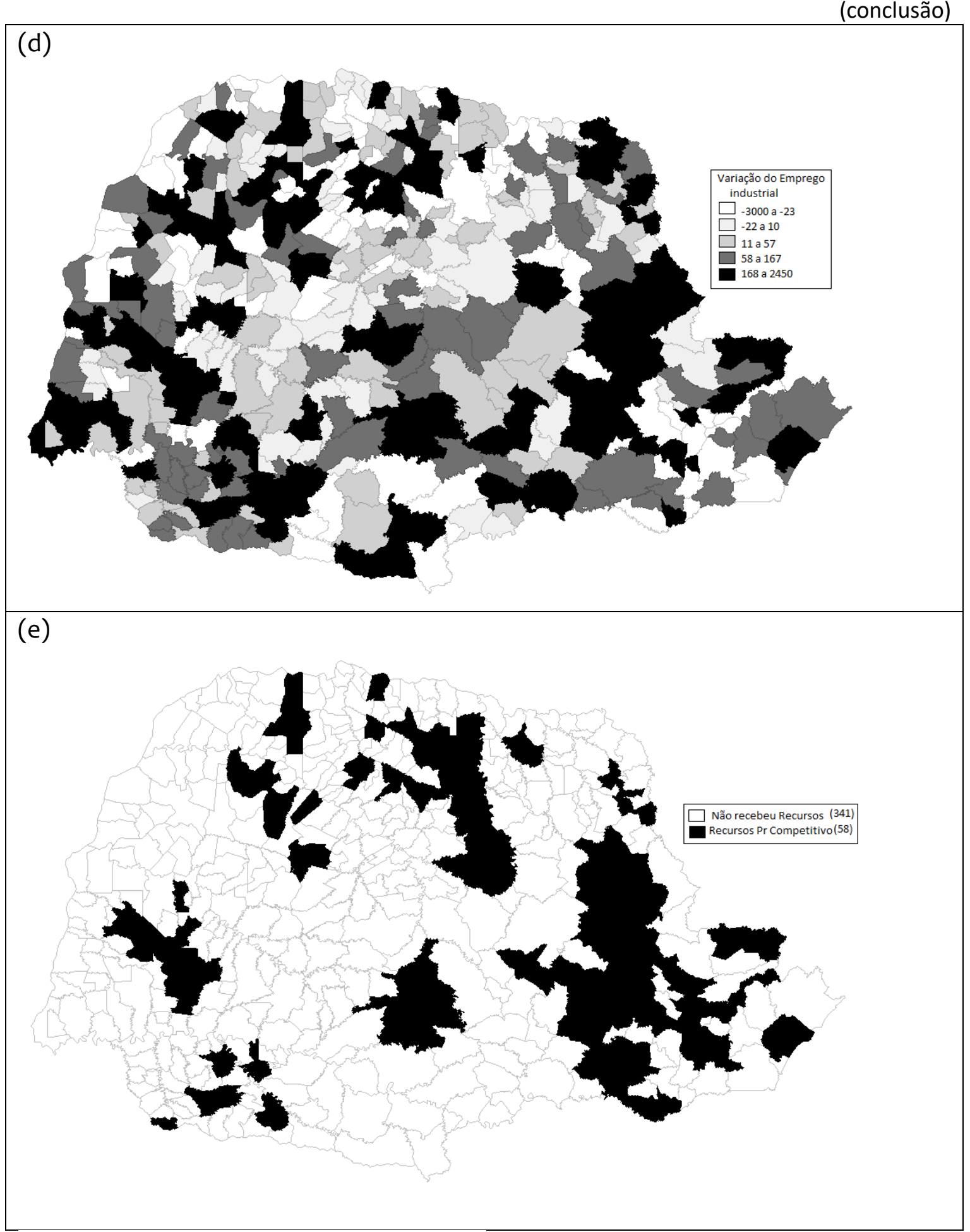

Fonte: Rais, com dados organizados pela pesquisa. 


\subsection{Efeitos do Paraná Competitivo sobre a geração de emprego e renda}

O Programa Paraná Competitivo tem como principal objetivo atrair novos investimentos, promovendo a descentralização regional do setor. Os dados apresentados anteriormente demonstram certa distribuição espacial desses investimentos ao longo do Paraná, embora estejam ainda próximos da capital do Estado. Ao todo, foram 58 municípios beneficiados com o Programa nestes anos iniciais, e alguns deles tinham o setor industrial incipiente.

Nesse sentido, a presença dos investimentos do Programa Paraná Competitivo, especialmente nesses espaços, pode ter promovido a formação de aglomerados produtivos, gerando externalidades positivas que podem induzir à dinamização de toda a economia. Além disso, os municípios do envoltório podem se beneficiar com os transbordamentos desses aglomerados, seja pela demanda de matérias-primas, instalações de empresas satélites, renda gerada através de salários, etc (HIRSCHMAN, 1958; KRUGMAN, 1991).

É nesse contexto que se avaliou o efeito do Programa Paraná Competitivo não só nos municípios beneficiados pelos investimentos, mas também investigou a ocorrência de transbordamentos desses efeitos para os municípios vizinhos, utilizando a econometria espacial.

Basicamente, quatro estimativas foram realizadas, todas investigando 0 efeito do Programa no município e nas regiões vizinhas. Na primeira estimativa, buscou-se identificar o efeito que o Programa Paraná Competitivo teve na industrialização dos municípios do Paraná, utilizando como proxy a variação absoluta do emprego industrial (variação entre 2010 e 2014)7. Os resultados reportados na Tabela 2 indicam a existência de efeitos positivos e significativos do programa na geração de postos de trabalho industrial, de forma que um aumento no montante investido tende, na média, a elevar a variação de empregos da indústria no município.

Ademais, seu efeito transcende as fronteiras do município, em que, pelo modelo SDEM [estimativa (4) da Tabela 2], consegue-se identificar um efeito positivo e significativo a um nível de significância de $10 \%$ do Programa nos municípios vizinhos, inferindo a existência de transbordamentos do investimento. Segundo a literatura, isso é consequência principalmente da instalação de empresas satélites no envoltório, e/ou de outras indústrias que são atraídas pela infraestrutura e pela concentração da mão de obra instalada no município vizinho, e/ou por outras economias de escala que são estendidas às regiões do envoltório do aglomerado produtivo.

Como nas análises anteriores, ficou visível uma concentração dos investimentos especialmente na RMC, separou-se o efeito do programa para tais municípios visando identificar se no processo de industrialização existem diferenças de resultados. Como corolário, usando uma dummy de interação entre "ser da RMC" e "receber investimentos do programa" (DummyRMC * Pr Com.). Nesse caso, obteve-se um coeficiente não significativo, o que indica não existir diferenças entre os efeitos na industrialização que o programa gera nos municípios da RMC e os que se obtém no interior do Estado.

7 O ano inicial correspondeu a 2010 pois foi a partir daí que se iniciou o Programa Paraná Competitivo, e o ano final é 2014, dada a disponibilidade dos dados. 
Ressalta-se que além das variáveis que captam a influência do Paraná Competitivo na variação do emprego industrial, utilizou-se outras variáveis de controle. Uma delas foi a distância da capital, que não se apresentou significativa na criação de postos de trabalho da indústria. Tal resultado é justificado potencialmente pelo avanço que se teve nos transportes e nas comunicações, fatores que minimizam a necessidade de se estar próximo, por exemplo, dos principais centros especializados no setor de serviço, segmento importante para o processo de industrialização.

Uma segunda variável de controle utilizada foi o emprego industrial inicial (In do emprego em 2010), que se apresentou negativa e estatisticamente significativa. Esse resultado infere a existência de um processo de convergência industrial no Paraná, de modo que aqueles municípios com um nível de emprego industrial inicial alto tiveram variações de crescimento dos postos de trabalho menores (e viceversa). Isso retrata a homogeneização que está em andamento ao longo do estado paranaense, fenômeno importante para o próprio processo de desenvolvimento econômico, com vistas a minimização das discrepâncias estaduais.

A produtividade industrial também se apresentou como importante para a criação dos empregos industriais, assim como o nível inicial de tecnologia existente na estrutura produtiva (Dummy alta/ média tecnologia). Portanto, se a indústria apresentar uma maior eficiência, independente do setor existente, maior tende a ser a dinâmica de emprego industrial subsequente; da mesma forma que, se a estrutura produtiva estiver inserida na produção de bens com maior valor agregado, produtos com maior intensidade tecnológica, maior tende a ser o dinamismo da sua indústria no período seguinte.

Por fim, a dependência espacial manifestada no termo de erro $(\lambda)$ é positiva e estatisticamente significativa, de modo que os efeitos sobre a variação do emprego industrial não advêm apenas do choque (representado pelo termo erro) do município, mas do transbordamento de choques oriundos de outros municípios vizinhos (Tabela 2). Portanto, outros fatores que conduzam à elevação do emprego em um município impactam positivamente na geração de emprego da região do envoltório.

Enfim, são vários os fatores que conduzem ao desenvolvimento da indústria paranaense, e o Programa Paraná Competitivo se apresenta como importante tanto nos municípios que foram beneficiados, como também naqueles municípios que estão no seu envoltório, tendo um efeito que transcendem as fronteiras territoriais. Tais inferências são importantes porque demonstram que o programa está atingindo seu principal objetivo, que é o de contribuir para a industrialização ao longo de todo o Estado. 
Tabela 2. Diagnósticos para dependência espacial, resultados e testes econométricos dos modelos de erro espacial (SEM) e Durbin espacial do erro (SDEM), cuja variável dependente é "Ln variação do emprego industrial" municípios do Paraná

\begin{tabular}{|c|c|c|c|c|}
\hline VARIÁVEIS & MQO (1) & SEM (2) & MQO (3) & SDEM (4) \\
\hline Constante & $\begin{array}{l}6,30^{*} \\
(0,00)\end{array}$ & $\begin{array}{l}6,32^{*} \\
(0,00)\end{array}$ & $\begin{array}{l}6,64^{*} \\
(0,00)\end{array}$ & $\begin{array}{l}6,65^{*} \\
(0,00)\end{array}$ \\
\hline Distância da capital & $\begin{array}{c}-0,0002 \\
(0,75)\end{array}$ & $\begin{array}{c}-0,0002 \\
(0,50)\end{array}$ & $\begin{array}{c}0,0002 \\
(0,77)\end{array}$ & $\begin{array}{l}0,0001 \\
(0,81)\end{array}$ \\
\hline Dummy alta/média tecnologia & $\begin{array}{l}0,67^{*} \\
(0,01)\end{array}$ & $\begin{array}{l}0,64^{*} \\
(0,00)\end{array}$ & $\begin{array}{l}0,66^{*} \\
(0,01)\end{array}$ & $\begin{array}{l}0,64^{*} \\
(0,00)\end{array}$ \\
\hline Ln emprego industrial inicial & $\begin{array}{l}-0,44^{*} \\
(0,00)\end{array}$ & $\begin{array}{l}-0,44^{*} \\
(0,00)\end{array}$ & $\begin{array}{l}-0,44^{*} \\
(0,00)\end{array}$ & $\begin{array}{l}-0,45^{*} \\
(0,00)\end{array}$ \\
\hline Ln produtividade inicial & $\begin{array}{l}2,56^{*} \\
(0,00)\end{array}$ & $\begin{array}{l}2,53^{*} \\
(0,00)\end{array}$ & $\begin{array}{l}2,50^{*} \\
(0,00)\end{array}$ & $\begin{array}{l}2,48^{*} \\
(0,00)\end{array}$ \\
\hline LnPr Competitivo & $\begin{array}{l}0,032 * \\
(0,05)\end{array}$ & $\begin{array}{l}0,032 * \\
(0,00)\end{array}$ & $\begin{array}{l}0,03^{*} \\
(0,05)\end{array}$ & $\begin{array}{l}0,03^{*} \\
(0,00)\end{array}$ \\
\hline W LnPr Competitivo & - & - & $\begin{array}{c}0,04 \\
(0,21)\end{array}$ & $\begin{array}{l}0,04 * * \\
(0,08)\end{array}$ \\
\hline Dummy RMC * Pr Com. & $\begin{array}{l}-0,18 \\
(0,81)\end{array}$ & $\begin{array}{c}-0,18 \\
(0,36) \\
(0,61)\end{array}$ & $\begin{array}{l}-0,20 \\
(0,78)\end{array}$ & $\begin{array}{c}-0,19 \\
(0,34)\end{array}$ \\
\hline$\lambda$ & - & $\begin{array}{l}0,13^{*} \\
(0,01)\end{array}$ & - & $\begin{array}{l}0,12^{*} \\
(0,01)\end{array}$ \\
\hline ML $\rho$ (defasagem) & 0,09 & - & 0,11 & - \\
\hline MLR $\rho$ (defasagem robusta) & 1,68 & - & 1,18 & - \\
\hline ML $\lambda$ (erro) & $2,15 * *$ & - & 1,78 & - \\
\hline MLR $\lambda$ (erro robusto) & $3,74^{*}$ & - & $2,88 *$ & - \\
\hline $\begin{array}{l}\text { Breusch-Pagantest } \\
\text { Jarque-Bera }\end{array}$ & $\begin{array}{c}73^{*} \\
75295^{*}\end{array}$ & $\begin{array}{l}- \\
-\end{array}$ & $\begin{array}{c}75^{*} \\
74652 *\end{array}$ & - \\
\hline
\end{tabular}

Fonte: resultado da pesquisa.

Nota: Entre parênteses refere-se ao p-valor da estatística t; $\left(^{*}\right)$ e $(* *)$ indica que é significativa a um nível de significância de $5 \%$ e 10\%, respectivamente. A matriz de convenção utilizada foi a de seis vizinhos, tendo em vista que foi a que apresentou os maiores resultados na investigação da distribuição espacial da estimativa. Pr Competitivo refere-se aos montantes investidos no Programa Paraná Competitivo em cada município; W é a defasagem espacial; Dummy RMC * Pr Com refere-se a uma dummy de interação entre "ser um município da RMC" e "ter investimento do Paraná Competitivo", sendo um (01) para os municípios que atendem a esses dois critérios e zero (0) caso contrário; Dummy alta+ média tecnologia, representando aqueles municípios que tiveram a presença, em 2010, de qualquer emprego na indústria de alta ou de média alta tecnologia [utilizouse a mesma classificação feita por Carvalho e Furtado (2005)], dando um (01) para estes e zero (0) para os demais; Ln é o logaritmo.

Ao gerar a industrialização, indiretamente outros setores são fomentados, num efeito multiplicador, como o comércio e o serviço, intensificando os postos de trabalho não só da indústria, mas de toda a economia. Essa é a perspectiva principalmente quando não se tem grandes vazamentos de renda de uma região. Nesse sentido que se analisou o efeito do Programa Paraná Competitivo sobre a variação do emprego total de cada município do Estado. 
Os resultados descritos na Tabela 3 [utilizando como referência a estimativa (4)] evidenciam um efeito positivo e estatisticamente significativo do Programa nos municípios que receberam tais inversões, de forma que um aumento nos investimentos tendem a elevar o número de empregos totais gerados. Porém, esses efeitos não transcendem as fronteiras dos municípios. Ou seja, não se conseguiu captar efeito significativo do Programa na geração de emprego totais dos municípios do envoltório.

A proximidade com um município que está dinamizando sua economia nem sempre exerce um efeito positivo sobre a economia do envoltório, principalmente porque nestes aglomerados tendem a concentrar, ex post, uma quantidade de serviços e comércio mais especializados, que se beneficiam das economias de aglomeração. De certo modo, essa oferta diferenciada de serviços e produtos pelo município dinamizado tende a atuar como uma força centrípeta dos recursos dos municípios próximos, freando os processos cumulativos que se teria nestas localidades, vazando parte da renda e não gerando os efeitos multiplicadores esperados. Essa seria uma das justificativas pela ausência de efeito do Programa na geração de emprego nos municípios do envoltório.

Portanto, ao mesmo tempo que os investimentos do Programa afetam a criação de novos postos de trabalho da indústria nos municípios vizinhos (Tabela 2), não se consegue o mesmo efeito quando se está analisando o emprego total [Tabela 3, estimativa (4)]. Esse poderia ser um dos pontos a serem trabalhados pelos planejadores públicos, em que, juntamente com o Programa Paraná Competitivo, tenha-se nas regiões periféricas o desenvolvimento de outras atividades, não esperando apenas o efeito de transbordamento do Paraná Competitivo, mas incentivando essas economias por meio de outros mecanismos de desenvolvimento regional, como, por exemplo, o incentivo ao empreendedorismo, a identificação de aptidões locais, etc.

No caso do emprego total, também se analisou a existência de diferenças quanto aos efeitos gerado pelo Programa entre os municípios da RMC e os do interior. Como corolário, não foi significativa essa diferença, de modo que o Programa tem o mesmo poder de fomentação de postos de trabalho seja nos municípios mais próximos à capital como também para aqueles localizados no interior do Estado.

Incluiu-se também variáveis de controle nas estimativas da Tabela 3. Para o emprego inicial, tal variável se apresentou positiva e significativa, demonstrando a existência de um processo de concentração do emprego total em poucos pontos do Estado. Como para a indústria obteve-se um processo de convergência (Tabela 2) e como o grau de informalidade da agropecuária tende a ser elevado, então, essa concentração espacial maior do emprego constatada nas estimativas da Tabela 3 está refletindo especialmente a inércia do setor terciário. Com efeito, em 2014, quatro municípios (Curitiba, Londrina, Maringá e Cascavel) respondiam por $50 \%$ de todo o emprego do setor de serviços e do comércio no Paraná, destacando que estes mesmos municípios, em 2010, respondiam por 51\% (RAIS, 2016). Ou seja, é centralizada a dinâmica desses setores, não mostrando uma tendência positiva quanto à homogeneização dessas atividades ao longo do Estado.

No caso da segunda variável de controle, referindo-se à distância da capital, apresentou-se positiva e significativa, ou seja, quanto mais longe da capital maior 
tende a ser a geração de empregos totais, em que, por estar espacialmente distante, não se tem perdas de renda e de emprego por bens e serviços adquiridos na capital.

Por fim, a defasagem espacial da variação do emprego total ( $\rho$ ) apresentou uma relação negativa com o processo de formação de novos postos de trabalho ao longo do Eestado, de modo que um município que apresente uma elevada variação no emprego total tende a gerar externalidades negativas aos seus vizinhos, diminuindo o nível de empregos do seu envoltório. A justificativa recai sobre os possíveis vazamentos de renda que se pode ter exatamente por se estar próximo a municípios que se encontram num processo de dinamização das suas economias, formando aglomerados, e, com efeito, concentrando mais as atividades de comércio e serviços por desfrutarem dos efeitos das economias de aglomerações.

Tabela 3. Diagnósticos para dependência espacial, resultados e testes econométricos dos modelos de defasagem espacial (SAR) e Durbin espacial (SDM), cuja variável dependente é "variação do emprego total"- municípios paranaenses

\begin{tabular}{lccccc}
\hline \multicolumn{1}{c|}{ VARIÁVEIS } & MQO (1) & SAR (2) & MQO (3) & SDM (4) \\
\hline Constante & $-284,97$ & $-146,96$ & 264,44 & $-201,32$ \\
& $(0,11)$ & $(0,42)$ & $(0,19)$ & $(0,31)$ \\
Distância da capital & $1,08^{*}$ & $0,90^{*}$ & $1,04^{*}$ & $1,03^{*}$ \\
& $(0,01)$ & $(0,02)$ & $(0,02)$ & $(0,02)$ \\
Emprego total inicial & $0,11^{*}$ & $0,11^{*}$ & $0,11^{*}$ & $0,11^{*}$ \\
& $(0,00)$ & $(0,00)$ & $(0,00)$ & $(0,00)$ \\
Pr Competitivo & $0,40^{*}$ & $0,42^{*}$ & $0,40^{*}$ & $0,41^{*}$ \\
& $(0,00)$ & $(0,00)$ & $(0,01)$ & $(0,0)$ \\
W Pr Competitivo & - & - & $-0,08$ & 0,29 \\
& & & $(0,83)$ & $(0,48)$ \\
Dummy RMC *Pr Com. & $-379,51$ & $-31,48$ & $-380,91$ & $-17,14$ \\
& $(0,36)$ & $(0,94)$ & $(0,35)$ & $(0,97)$ \\
$\rho$ & - & $-0,06^{*}$ & - & $-0,06^{*}$ \\
& & $(0,02)$ & & $(0,01)$ \\
\hline ML $\rho$ (defasagem) & $7,56^{*}$ & & $8,30^{*}$ & \\
MLR $\rho$ (defasagem robusta) & $5,92^{*}$ & & $6,47^{*}$ & \\
ML $\lambda$ (erro) & $2,18^{*}$ & & 2,28 & \\
MLR $\lambda$ (erro robusto) & 0,54 & & 0,45 & \\
\hline BreuchPagantest & 3,7 & & \\
Jarque-Bera & $88856^{*}$ & & & \\
\hline
\end{tabular}

Fonte: resultado da pesquisa.

Portanto, o Programa Paraná Competitivo tende a exercer efeito positivo apenas na variação do emprego total do município beneficiado pelas inversões, não conseguindo externalidades para o seu envoltório. E o mesmo fenômeno se processa para a massa salarial [Tabela 4, estimativa (4)], consequência direta dos potenciais vazamentos de renda dos municípios vizinhos para os que estão num processo de formação de aglomerados. 
Tabela 4. Diagnósticos para dependência espacial, resultados e testes econométricos dos modelos de defasagem espacial (SAR) e Durbin espacial (SDM), cuja variável dependente é "Ln variação da massa salarial" - municípios paranaenses

\begin{tabular}{lcc|c|c}
\hline \multicolumn{1}{c|}{ VARIÁVEIS } & MQO & SAR & MQO & SDM \\
\hline Constante & $0,67^{*}$ & $0,5^{*}$ & $0,59^{*}$ & $0,50^{*}$ \\
& $(0,00)$ & $(0,00)$ & $(0,00)$ & $(0,00)$ \\
Ln massa salarial inicial & $-0,02^{*}$ & $-0,03^{*}$ & $-0,02^{*}$ & $-0,02^{*}$ \\
& $(0,00)$ & $(0,00)$ & $(0,00)$ & $(0,00)$ \\
Ln variação do salário médio & $0,44^{*}$ & $0,43^{*}$ & $0,44^{*}$ & $0,43^{*}$ \\
& $(0,00)$ & $(0,00)$ & $(0,00)$ & $(0,00)$ \\
LnPr Competitivo & $0,007^{*}$ & $0,008^{*}$ & $0,007^{*}$ & $0,008^{*}$ \\
W LnPr Competitivo & $(0,00)$ & $(0,00)$ & $(0,00)$ & $(0,00)$ \\
& - & - & $-0,003$ & $-0,003$ \\
DummyRMC * Pr Com. & $-0,09^{* *}$ & $-0,06$ & $(0,12)$ & $(0,15)$ \\
& $(0,06)$ & $(0,21)$ & $(0,11)$ & $(0,35)$ \\
$\rho$ & & $0,39^{* *}$ & - & $0,43^{* *}$ \\
& & $(0,10)$ & & $(0,07)$ \\
\hline ML $\rho$ (defasagem) & $3,41^{*}$ & & $3,36^{*}$ & \\
MLR $\rho$ (defasagem robusta) & 0,30 & & $2,54^{*}$ & \\
ML $\lambda$ (erro) & $3,11^{*}$ & & 2,05 & \\
MLR $\lambda$ (erro robusto) & 0,0 & & 1,23 & \\
\hline BreuchPagan test & $65^{*}$ & & $102^{*}$ & \\
Jarque-Bera & $38^{*}$ & & & \\
\hline
\end{tabular}

Fonte: resultado da pesquisa.

Além da massa salarial, investigou-se os efeitos do Programa Paraná Competitivo sobre o salário médio. Destaca-se que o salário médio é de suma importância, tendo em vista que o mesmo é frequentemente utilizado como proxy da produtividade. Os resultados da Tabela 5 mostram que o programa consegue exercer uma influência positiva e estatisticamente significativa sobre o salário médio do município, bem como o salário médio dos municípios do seu envoltório.

Especialmente no caso daqueles municípios cujo dinamismo da indústria não era tão intenso em 2010, mas que receberam recursos do programa (correspondendo a $83 \%$ dos municípios beneficiados), as inversões que ocorreram induziram a formação de empregos industriais, os quais tenderam a ter remunerações maiores que os demais setores, especialmente quando comparado ao comércio, justificando o efeito positivo e significativo do programa sobre o salário médio.

Ao mesmo tempo, essa influência não ficou restrita às fronteiras desses municípios, afetando positivamente a variação do salário médio dos municípios vizinhos [Tabela 5, estimativa (4)]. Com efeito, conforme visto na estimativa da Tabela 2 [estimativa (4)], o programa afetou a variação do emprego industrial dos municípios do envoltório. Nesse sentido, considerando a mesma lógica descrita anteriormente, especialmente em municípios com um setor secundário menos desenvolvido, quando se tem variação positiva no emprego industrial nestes espaços, tende-se a elevar o salário médio. Portanto, ao se ter inversões do Paraná 
Competitivo, consegue-se não apenas alavancar o salário médio do município beneficiado, mas também contribuir positivamente para a variação do salário médio das regiões vizinhas.

Um adendo se deve fazer no que se refere aos municípios que mais se beneficiaram com a elevação do salário médio. Conforme os resultados da Tabela 5 , aqueles que participam do Programa e que estão localizados na RMC tendem a ter uma elevação maior no seu salário médio. Potencialmente, tal resultado advém da estrutura produtiva que já existe nestes espaços, o que lhes garantem certa produtividade, com existência de spillovers tecnológicos, dentre outras externalidades, conduzindo a uma eficiência maior e repercutindo no seu salário médio.

Por fim, no caso das variáveis de controle, ressalta-se que o nível tecnológico da indústria que se faz presente na estrutura produtiva também é determinante do salário médio, em que ao ter indústrias de alta ou média alta tecnologia, tendem a ter um salário médio mais elevado. Ademais, identificou-se um processo de convergência do salário médio, de forma que aqueles municípios com maiores níveis iniciais de salários médios tiveram, na média, menores taxas de crescimentos dos seus salários médios.

No caso da dependência espacial manifestada no termo de erro $(\lambda)$, apresentou-se positiva e estatisticamente significativa, de modo que os efeitos sobre a variação do salário médio não advêm apenas do choque (representado pelo termo erro) do município, mas do transbordamento de choques oriundos de outros municípios vizinhos (Tabela 5). Portanto, outros fatores que conduzam a elevação do salário médio em um município impactam positivamente na geração de ganhos de produtividade (salário médio) da região do envoltório. 
Tabela 5 - Diagnósticos para dependência espacial, resultados e testes econométricos dos modelos de erro espacial (SEM) e Durbin espacial do erro (SDEM), cuja variável dependente é " Ln variação da média salarial" - municípios

\section{do Paraná}

\begin{tabular}{|c|c|c|c|c|}
\hline VARIÁVEIS & MQO (1) & SEM (2) & MQO (3) & SDEM (4) \\
\hline Constante & $\begin{array}{l}2,27^{*} \\
(0,00)\end{array}$ & $\begin{array}{l}2,34^{*} \\
(0,00)\end{array}$ & $\begin{array}{l}2,33^{*} \\
(0,00)\end{array}$ & $\begin{array}{l}2,40^{*} \\
(0,00)\end{array}$ \\
\hline Ln média salarial inicial & $\begin{array}{l}-0,30 * \\
(0,00)\end{array}$ & $\begin{array}{l}-0,31^{*} \\
(0,00)\end{array}$ & $\begin{array}{l}-0,31^{*} \\
(0,00)\end{array}$ & $\begin{array}{l}-0,32 * \\
(0,00)\end{array}$ \\
\hline $\begin{array}{l}\text { Dummy alta/média } \\
\text { tecnologia }\end{array}$ & $\begin{array}{l}0,03^{*} \\
(0,00)\end{array}$ & $\begin{array}{l}0,03^{*} \\
(0,00)\end{array}$ & $\begin{array}{l}0,03^{*} \\
(0,00)\end{array}$ & $\begin{array}{l}0,03^{*} \\
(0,00)\end{array}$ \\
\hline Ln variação massa salarial & $\begin{array}{l}0,11^{*} \\
(0,00)\end{array}$ & $\begin{array}{l}0,11^{*} \\
(0,01)\end{array}$ & $\begin{array}{l}0,11^{*} \\
(0,00)\end{array}$ & $\begin{array}{l}0,11^{*} \\
(0,01)\end{array}$ \\
\hline DummyRMC * Pr Com. & $\begin{array}{l}0,07^{*} \\
(0,01)\end{array}$ & $\begin{array}{l}0,07^{*} \\
(0,05)\end{array}$ & $\begin{array}{l}0,06 * \\
(0,01)\end{array}$ & $\begin{array}{l}0,06 * * \\
(0,08)\end{array}$ \\
\hline LnPr Competitivo & $\begin{array}{l}0,002^{*} \\
(0,01)\end{array}$ & $\begin{array}{l}0,002^{*} \\
(0,00)\end{array}$ & $\begin{array}{c}0,002 * \\
(0,01)\end{array}$ & $\begin{array}{l}0,002^{*} \\
(0,00)\end{array}$ \\
\hline W LnPr Competitivo & - & - & $\begin{array}{c}0,002 * * \\
(0,08)\end{array}$ & $\begin{array}{l}0,002^{*} \\
(0,05)\end{array}$ \\
\hline$\lambda$ & - & $\begin{array}{l}0,14^{*} \\
(0,02)\end{array}$ & - & $\begin{array}{l}0,14^{*} \\
(0,03)\end{array}$ \\
\hline ML $\rho$ (defasagem) & 0,48 & & 0,44 & \\
\hline MLR $\rho$ (defasagem robusta) & $3,28 * *$ & & $3,33^{* *}$ & \\
\hline ML $\lambda$ (erro) & $2,96 * *$ & & $2,99 * *$ & \\
\hline MLR $\lambda$ (erro robusto) & $5,78^{*}$ & & $5,89 *$ & \\
\hline $\begin{array}{l}\text { Breusch-Pagantest } \\
\text { Jarque-Bera }\end{array}$ & $\begin{array}{c}13^{*} \\
868^{*}\end{array}$ & & $\begin{array}{l}12,7^{*} \\
846^{*}\end{array}$ & \\
\hline
\end{tabular}

Fonte: resultado da pesquisa.

\section{CONSIDERAÇÕES FINAIS}

Nos últimos anos, a trajetória industrial do Paraná demonstrou um processo de descentralização do setor, em parte, o Programa Paraná Competitivo contribuiu para isso. Claro que ainda se tem uma centralização dos principais investimentos no corredor entre a RMC e os Campos Gerais, mas se teve um deslocamento de inversões importantes naqueles municípios interioranos cuja industrialização era incipiente.

Os resultados econométricos mostram a efetividade do Programa tanto na geração de empregos industriais como também na fomentação de empregos totais, na massa salarial e no salário médio dos 58 municípios participantes. No entanto, as externalidades para os municípios vizinhos dos receptores dos investimentos não são tão fortes, apresentando-se significativa apenas para o emprego industrial e a média salarial. Potencialmente, tal resultado está atrelado aos vazamentos que se tem, centralizando as principais atividades, principalmente do setor terciário, naqueles municípios receptores dos recursos do programa, por conduzir à formação de aglomerados produtivos. 
Nesse sentido, políticas de desenvolvimento regional e local integradas ao Programa Paraná Competitivo se fazem necessárias, especialmente para os municípios do interior do Estado do Paraná, como melhoria da infraestrutura de transportes (duplicação e integração de rodovias, ferrovias, portos e aeroportos), de formação de mão de obra em nível técnico e superior, de empreendedorismo, de capacitação de prefeituras municipais, no sentido de aumentar sua probabilidade de receber investimentos de firmas do setor industrial ou acesso às externalidades positivas potenciais provenientes da industrialização de municípios vizinhos.

É importante aqui mencionar que não obstante todo o esforço metodológico empregado no presente trabalho, a análise dos efeitos do Programa Paraná Competitivo, sobre a geração de emprego e renda nos municípios paranaenses, ainda pode ser aprimorada, por meio da utilização de outras metodologias (como matriz insumo-produto, por exemplo) ou, ainda, com a inclusão de outras variáveis de controle no modelo econométrico.

Assim, espera-se que o presente trabalho seja um ponto de partida para que novos estudos sejam desenvolvidos, a fim de avaliar os impactos do Programa Paraná Competitivo na economia paranaense. Destaca-se que essa cultura de avaliação de política pública é de suma importância, pois pode servir de subsídio para os gestores do governo avaliarem os rumos do Programa, possibilitando os ajustes necessários para que os objetivos traçados sejam realmente cumpridos.

\section{REFERÊNCIAS}

ALMEIDA, E. Econometria Espacial Aplicada, Editora Alínea, Campinas, 2012.

CROCCO, M. A., GALINARI, R., SANTOS, E, LEMOS, M. B. \& SIMÕES, R. Metodologia de identificação de aglomerações produtivas locais, Nova Economia, v.16, p.211-241, 2006.

FURTADO, A. T.; CARVALHO, R. Q. Padrões de intensidade tecnológica da indústria brasileira: um estudo comparativo com os países centrais. São Paulo em Perspectiva, São Paulo, v. 19, n.1, p. 70-84, jan./mar. 2005.

HIRSCHMAN, Albert O. The Strategy of Economic Development. New Haven, Yale University Press, 1958.

IPARDES. Instituto Paranaense de Desenvolvimento Econômico e Social. Paraná: Diagnóstico Social e Econômico. Curitiba: IPARDES, 2003, 114p.

JACOBS, J. The Economy of Cities. Vintage, New York, 1969.

KALDOR, N. The Case for Regional Policies, Scottish Journal of Political Economy, November, 1970.

KRUGMAN, P. R. Geography and Trade. Cambridge: MIT Press, 1991. 
LEWIS, W. Arthur. Economic Development with Unlimited Supplies of Labour, The Manchester School. Maio/1954

NURKSE, Ragnar. Problems of Capital Formation in Underdeveloped Countries. Oxford, Basil Blackwell, 1955

RAIS. Acesso ao sistema. Disponível em< http://bi.mte.gov.br/bgcaged/login.php>. Acesso em 2016.

ROSENSTEIN-RODAN, Paul N. Problems of Industrialization of Eastern and SouthEastern Europe, Economic Journal. junho/setembro 1943

ROSTOW, W. W. The Stages of Economic Growth, A Non-Communist Manifesto. Cambridge, The University Press, 1964.

SABOIA, J.; KUBRUSLY, L. S. Diferenciais Regionais e Setoriais na Indústria Brasileira. Revista de Economia Aplicada, v. 12, p. 125-149, 2008.

SANO, H; FILHO, M. J. F. M. As técnicas de avaliação da eficiência, eficácia e efetividade na gestão pública e sua relevância para o desenvolvimento social e das ações públicas. Revista Desenvolvimento em Questão, ano 11, n² 22, jan./abr. 2013.

SILVA, L. N. S.; BORGES, M. J.; PARRÉ, J. L. Distribuição Espacial da Pobreza no Paraná. In: XVI ENCONTRO DE ECONOMIA DA REGIÃO SUL - ANPEC Sul. Anais... Curitiba, Paraná, 2013.

Augusta Pelinski Raiher. Doutora em economia pela Universidade Federal do Rio Grande do Sul. Professora do programa de Pós Graduação em economia, do Programa de Pós Graduação em ciências sociais e do curso de economia da Universidade Estadual de Ponta Grossa.apelinski@gmail.com

Hermes Higachi. Doutor em Ciência Econômica pela Universidade Estadual de Campinas, e pós-doutorado em economia pela FEA/USP. Professor do Programa de Pós Graduação em economia e do curso de economia da Universidade Estadual de Ponta Grossa. hhigachi@gmail.com

Alex Sander Souza do Carmos. Doutor em Desenvolvimento Economico pela Universidade Federal do Paraná. Professor do Programa de Pós Graduação em economia e do curso de economia da Universidade Estadual de Ponta Grossa. alexsscarmo@hotmail.com 